ECCOMAS

Proceedia
EUROGEN 2021

$14^{\text {th }}$ ECCOMAS Thematic Conference on Evolutionary and Deterministic Methods for Design, Optimization and Control N. Gauger, K. Giannakoglou, M. Papadrakakis, J. Periaux (eds.) Streamed from Athens, Greece, 28-30 June 2021

\title{
THE EFFECT OF THE ASSUMED INHERENT DUMPING IN THE TUNING OF TUNED MASS DAMPERS
}

\author{
Ayla Ocak ${ }^{1}$, Gebrail Bekdaş ${ }^{1}$ and Sinan Melih Nigdeli \\ ${ }^{1}$ Department of Civil Engineering, Istanbul University - Cerrahpasa \\ Avcrlar,Istanbul, Turkey \\ e-mail: aylaocak@outlook.com, bekdas@istanbul.edu.tr, melihnig@istanbul.edu.tr
}

\begin{abstract}
As known, the damping ratio of structures is assumed as a constant value. This constant value is also used in the analysis of structures and these analysis results are used in the optimum design of active and passive control systems. In the present study, the assumed value of inherent damping of the structure is tested on tuned mass dampers that are used in the structures to reduce responses resulting from earthquakes. For this purpose, three methods are investigated by considering the increase or decrease of the damping coefficient of the superstructure. The first method is the usage of equations of Den Hartog which does not consider the inherent dumping of the structure. Secondly, the basic equations of Sadek et al. that include the inherent dumping for the optimum parameters are examined. Finally, a metaheuristic-based optimization approach using the Jaya algorithm (JA) was used in the investigation.
\end{abstract}

Keywords: Optimization, Dumping, Tuned Mass Dampers, Jaya Algorithm. 


\section{INTRODUCTION}

Mass dampers are devices that Hermann Frahm [1] invented in 1909 to prevent machine vibration on board, in which Ormondroyd and Den Hartog [2] put forward the first theoretical studies for this type of damper. The fact that TMDs became a part of the design took its place in architecture with research by Mcnamara [3]. Considering the mass of the structure on which TMDs are placed, SDOF has a mass of approximately 5\% of the structure for a structure [4-5]. Similar to other passive damping systems, these systems, which convert mechanical energy to damping energy as a working principle, have become a preferred system for building vibration control in terms of not needing external energy, easy cost and maintenance and applicability to old buildings. Looking at the areas of use, we can see that the bridge, tower, etc. exposed to wind forces. It is seen that it is placed in structures, earthquake-effect structures and in the types of structures that are negativized by other vibrations. An example is folded pendulum with a movement ampliated capacity of $\pm 48 \mathrm{~cm}$, with a mass ratio of $4.5 \%$, to 450 tons for the 40 storey Socar Tower (Figure 1 and 2), which was built in 2010, in Baku, capital of Azerbaijan. Another example used in TMD, Alphabetic Tower (Figure 3) in Batumi, Georgia, used standard TMD with a $3.5 \%$ mass ratio of 62.85 tons with a movement amplitude of $\pm 24 \mathrm{~cm}$ [6].
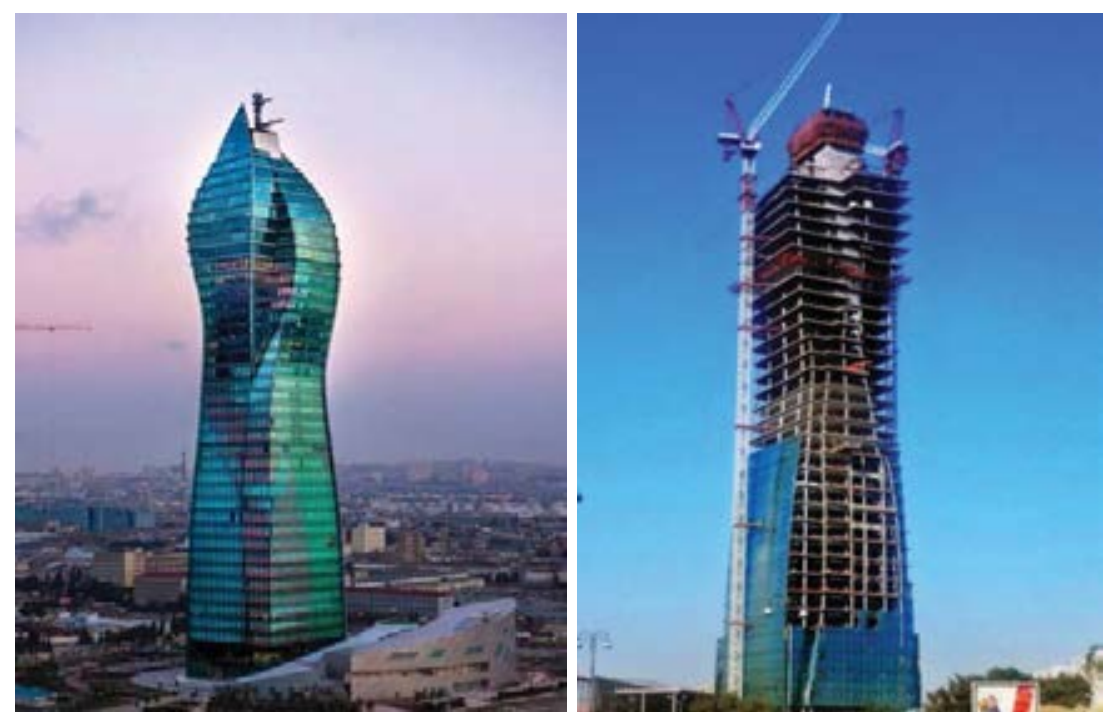

\section{Figure 1. Socar Tower [7]}
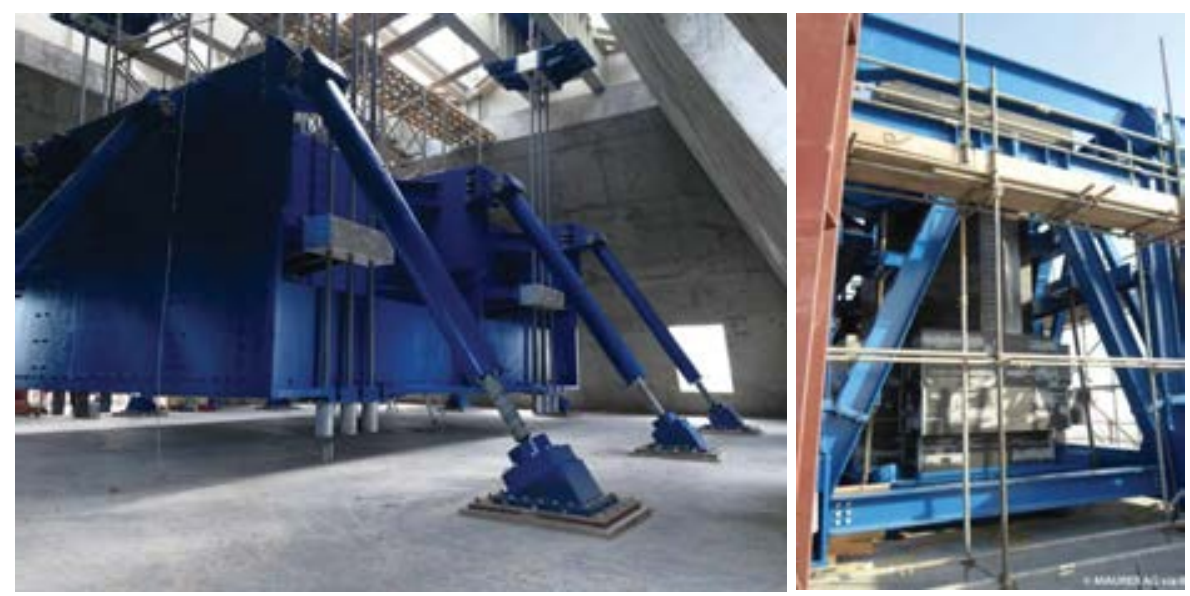

Figure 2. Socar Tower Folded Pendilum TMD [8] 


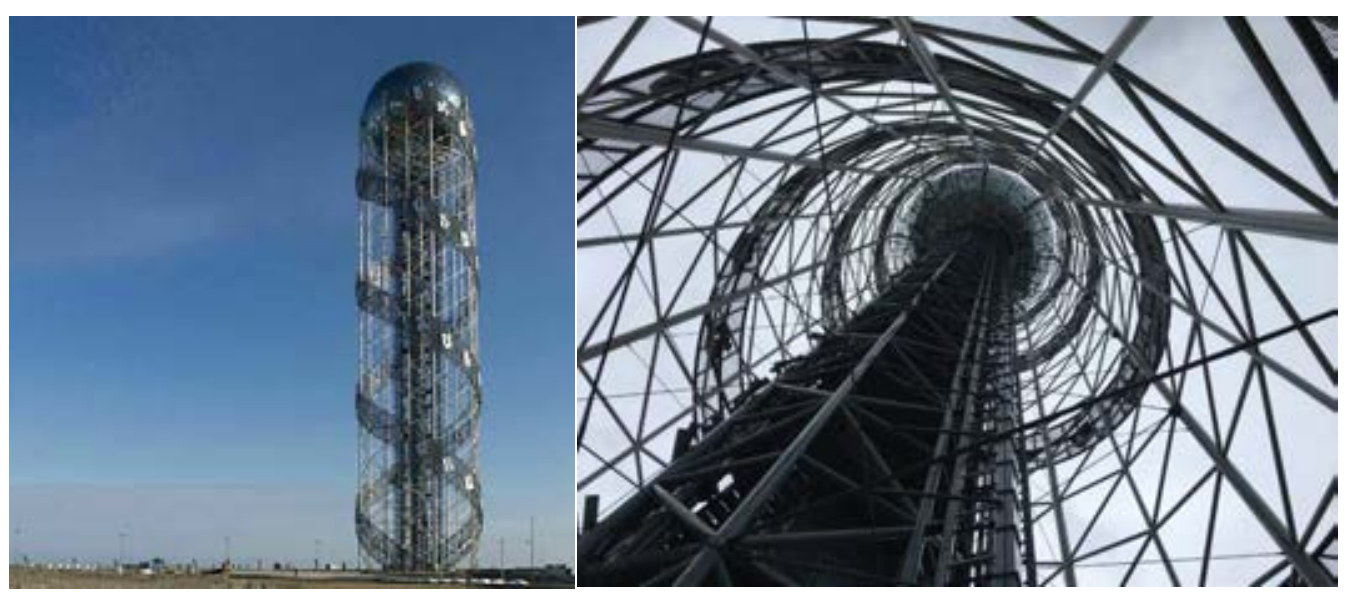

Figure 2. Alphabetic Tower [9]

TMDs are connected to the structure with the help of spring and damper. The most appropriate account of the spring and damping parameters found in these devices is important for the efficiency of the device. A mode must be defined to the TMD to control the vibration of the structure. This defined value must be selected in accordance with the critical frequency of the structure. As a result of the theoretical studies carried out by Den Hartog, considering the mass ratio of TMD and structure $(\mu)$ in accordance with the SDOF structure, the optimum frequency $\left(f_{\mathrm{opt}}\right)$ is given in Equation (1) and the optimum damping ratio ( $\left.\xi_{\mathrm{d}, \mathrm{opt}}\right)$ is given in Equation (2). In the equations, the frequency of the structure is $\omega_{\mathrm{s}}$ and the frequency of TMD is $\omega_{\mathrm{d}}$, opt. The mass and damping coefficient of TMD is $m_{d}$ and $c_{d}$, respectively. In Equation (3), the stiffness coefficient of TMD is accounted for $\mathrm{k}_{\mathrm{d}}$.

$$
\begin{gathered}
f_{o p t}=\frac{w_{d, o p t}}{w_{s}}=\frac{1}{1+\mu} \\
\xi_{d, o p t}=\frac{c_{d}}{2 m_{d} \omega_{d, o p t}}=\sqrt{\frac{3 \mu}{8(1+\mu)}} \\
k_{d}=\omega_{d, o p t}{ }^{2} m_{d}
\end{gathered}
$$

Den Hartog developed formulations for optimum damping parameters in his book called mechanical vibrations [10]. In the following years, different formulations were produced other than these assumptions [11-15]. Besides, Sadek at al. added the natural damping of the structure to the formulation. Equations 4 and 5 show these formulas [16].

$$
\begin{gathered}
f_{o p t}=\frac{1}{1+\mu}\left[1-\xi \sqrt{\frac{\mu}{1+\mu}}\right] \\
\xi_{d, o p t}=\frac{\xi}{1+\mu}+\sqrt{\frac{\mu}{1+\mu}}
\end{gathered}
$$

The optimization process has several advantages in terms of its ability to compare multiple results at the same time in achieving the design variables. Metaheuristic algorithms using numerical reputations for optimum design variables are a variant of an appropriate optimization for the detection of TMD efficiency. There are varieties of metaheuristic algorithms such as genetic algorithm (GA) [17-26], Bionic Algorithm [27], Ant colony optimization (ACO) [28], Particle swarm optimization (PSO) [29-30], Harmony search algorithm (HS) [31-36], Artificial 
bee colony optimization (ABC) [37], Teaching-Learning-Based optimization (TLBO) [34, 35, 38], Flower pollination algorithm (FPA) [34, 35, 39, 40], Bat Algorithm (BA) [41], Jaya Algorithm (JA) [42, 43].

In this study, Jaya algorithm optimization and equations of Sadek et al. [16] and Den Hartog [10] are used for a single degree of freedom system (SDOF). Then, the optimum values obtained as a result of these 3 methods were compared in case of the change of the damping ratio of the structure that is different from the assumed value in the optimization.

\section{DYNAMIC ANALYSIS OF STRUCTURE}

Simulink model was created on MATLAB [44] for optimization. The optimum parameters of TMD was calculated and results under earthquake data within the defined time interval (0.001) are obtained for far-field ground motion records given in FEMA P-695: Quantification of Building Seismic Performance Factors [45]. SDOF model used in the study is shown schematically in Figure 4. The mass, rigidity and damping coefficient of the SDOF structure are expressed as $\mathrm{m}, \mathrm{k}$ and $\mathrm{c}$, respectively. The mass, rigidity and damping coefficient of TMD added to the structure is $m_{d}, k_{d}, c_{d}$, respectively and the displacement in structure is shown as $\mathrm{x}$ and TMD displacement is shown as $\mathrm{x}_{\mathrm{d}}$.

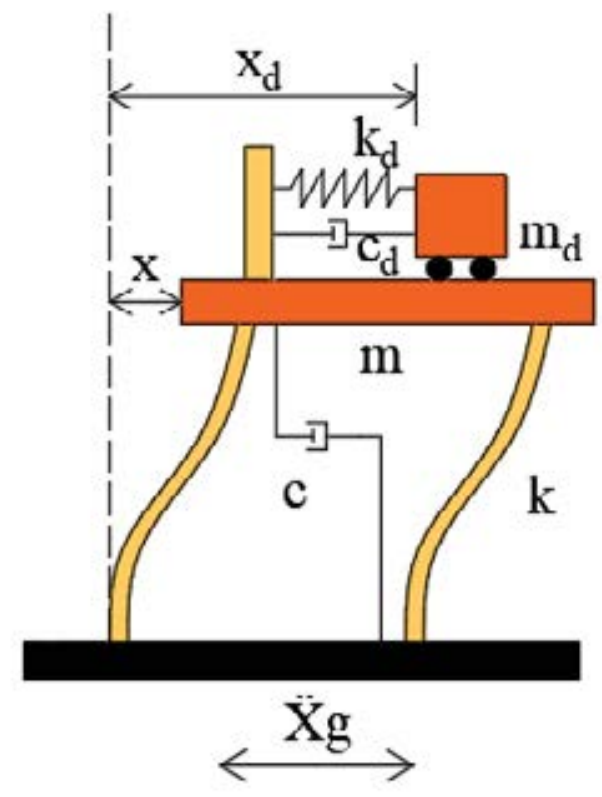

Figure 4. The physical model

Ground acceleration is shown by $\ddot{x}_{\mathrm{g}}$. The motion equation for the SDOF structure used in the study is given in Equation 6. By including TMD, the equations of the motion of the 2 degrees of freedom system are shown as Equations 7 and 8.

$$
\begin{gathered}
m \ddot{x}+c \dot{x}+k x=-m \ddot{x}_{g} \\
m \ddot{x}+\left(c+c_{d}\right) \dot{x}-c_{d} \dot{x}_{d}+\left(k+k_{d}\right) x+k_{d} x_{d}=-m \ddot{x}_{g} \\
m_{d} \ddot{x}_{d}-c_{d} \dot{x}+c_{d} \dot{x}_{d}-k_{d} x+k_{d} x_{d}=-m \ddot{x}_{g}
\end{gathered}
$$




\section{THE OPTIMIZATION METHODOLOGY}

Using motion equations and TMD parameter calculations from the work of Den Hartog [10] and Sadek et al. [16], the main structure and damping parameters were calculated. For the earthquake records, which were then excited to the SDOF system, the maximum critical acceleration and displacement that will occur in the main structure were determined. The JA [45] developed by Rao, a metaheuristic algorithm inspired by victory, was selected for system optimization. With the codes prepared on the Matlab, JA was applied to optimize the system and maximum acceleration and displacements were obtained for the same earthquake records. The damping value of the SDOF structure was increased by 100 between $500-1500 \mathrm{Ns} / \mathrm{m}$ and the critical displacement and total acceleration values for all earthquake records were determined by the oprimum values of Den Hartog, Sadek et al. and JA. It has been computed and tabulated without the TMD structure and TMD structure.

The following is the equation for JA shown as Equation 9. The process of optimization based on a random assignment using the best and worst solution for the objective function obtained from Rao's work [45].

$$
X_{\text {new }, i}=X_{\text {old }, i}+r_{1}\left(X_{\text {best }}-\left|X_{\text {old }, i}\right|\right)-r_{2}\left(X_{\text {worst }}-\left|X_{\text {old }, i}\right|\right)
$$

$X_{\text {best }}$ and $X_{\text {worst }}$ used to obtain new solutions are the best solution and worst solution, respectively. The expression that randomly assigns between 0 and 1 is written as $r_{1}$ and $r_{2}$. The newly founded result for the $i^{\text {th }}$ solution $\left(X_{\text {new }, i}\right)$ is obtained via the existing one shown as $X_{\text {old }, i}$. The process of generating optimized new solutions and deriving existing solutions is continued for the number of iterations.

\section{THE OPTIMUM RESULTS}

For the investigation, the parameters of the SDOF structure are taken as $1000 \mathrm{~kg}, 120000$ $\mathrm{N} / \mathrm{m}$ and $1000 \mathrm{Ns} / \mathrm{m}$ for $\mathrm{m}, \mathrm{k}$, and c, respectively. By using these parameters, the optimum results for a 5\% mass of TMD are given in Table 1 for different approaches.

Table 1: The optimum results.

\begin{tabular}{crrr}
\hline Method & Den Hartog [10] & Sadek et al. [16] & JA \\
\hline$m_{d}(\mathrm{~kg})$ & 50 & 50 & 50 \\
$c_{d}(\mathrm{Ns} / \mathrm{m})$ & 139.4143 & 270.2948 & 79.4850 \\
$k_{d}(\mathrm{~N} / \mathrm{m})$ & 5442.1769 & 5334.3060 & 7467.6313 \\
\hline
\end{tabular}

\section{DISCUSSION AND CONCLUSIONS}

The investigation was done by taking 5\% less and more of the assumed damping valur with $100 \mathrm{Ns} / \mathrm{m}$ intervals. The displacement and acceleration maximum values are reported in Table 2 for the critical excitation with the most effect on the structure. This record is the MUL279 record of the 1994 Northridge earthquake.

As seen from Table 2, the displacement values are reduced by $30.3 \%, 37.4 \%$ and $42.5 \%$ for the methods of Sadek et al., Den Hartog and JA, respectively. The reduction percentages for the acceleration are 32\%, 37.7\% and 48.6\% for Sadek et al., Den Hartog and JA, respectively. It is seen that the best method is the use of optimization algorithms like JA. 
Table 2: The responses for different damping coefficient values.

\begin{tabular}{ccccccccc}
\hline \multirow{2}{*}{$\begin{array}{c}c \\
(\mathrm{Ns} / \mathrm{m})\end{array}$} & \multicolumn{2}{c}{ Without TMD } & \multicolumn{6}{c}{ With TMD } \\
\cline { 2 - 9 } & & & \multicolumn{2}{c}{ Sadek et. al. [16] } & \multicolumn{2}{c}{ Den Hartog $[10]$} & \multicolumn{2}{c}{ JA } \\
\hline 500 & 0.2305 & 27.6931 & 0.1486 & 17.3602 & 0.1288 & 15.5914 & 0.1281 & 13.4663 \\
600 & 0.2177 & 26.1615 & 0.1425 & 16.6482 & 0.1240 & 15.0228 & 0.1211 & 12.8844 \\
700 & 0.2058 & 24.7464 & 0.1370 & 16.0236 & 0.1199 & 14.4949 & 0.1150 & 12.3404 \\
800 & 0.1948 & 23.4298 & 0.1321 & 15.4692 & 0.1166 & 13.9941 & 0.1102 & 11.8342 \\
900 & 0.1846 & 22.2273 & 0.1275 & 14.9393 & 0.1135 & 13.5810 & 0.1056 & 11.3630 \\
1000 & 0.1765 & 21.2588 & 0.1231 & 14.4474 & 0.1105 & 13.2404 & 0.1014 & 10.9210 \\
1100 & 0.1688 & 20.3615 & 0.1190 & 13.9781 & 0.1076 & 12.9108 & 0.0990 & 10.6213 \\
1200 & 0.1616 & 19.5112 & 0.1151 & 13.5300 & 0.1049 & 12.5975 & 0.0968 & 10.3847 \\
1300 & 0.1549 & 18.7241 & 0.1114 & 13.1140 & 0.1023 & 12.3001 & 0.0946 & 10.1603 \\
1400 & 0.1487 & 17.9807 & 0.1079 & 12.7154 & 0.0998 & 12.0122 & 0.0926 & 9.9429 \\
1500 & 0.1427 & 17.2813 & 0.1045 & 12.3343 & 0.0973 & 11.7334 & 0.0906 & 9.7322 \\
\hline
\end{tabular}

For the damping values less than the assumed value, the performance of the TMD increases. For example, a $51.4 \%$ reduction occurs for the acceleration, when c value is the minimum by using JA. The opposite can be said for the increasing damping values. By this conclusion, it is seen that TMDs are more effective for the system with low inherent damping. Also, TMDs are effective when the damping coefficient value is different from the assumed one.

\section{REFERENCES}

[1] Frahm H. Device for damping of bodies. U.S. Patent No: 989,958, 1911.

[2] Ormondroyd, J. and Den Hartog, J.P., 1928. The theory of the dynamic vibration absorbs. Trans., ASME, Applied Mechanics, 50, 9-22

[3] McNamara, R.J., 1977. Tuned mass dampers for buildings. Journal of the Division, 103(9), 1785-1798.

[4] Vickery, B.J., Isyumov, N. and Davenport, A.G., 1983. The role of dumping, mass and acceleration. J. Wind Eng. Ind. Aerodyn., 11(1-3), 285-294.

[5] Rana, R. and Soong, T. T., 1998. Parametric study and simplified design of tuned mass dampers. Engineering structures, 20(3), 193-204.

[6] Maurer AG, Vibration Control of Tall Buildings: Maurer Tuned Mass Dampers.

[7] International Database and Gallery of Structures, https://structurae.net/en/products-services/400-ton-pendulum-in-the-onion

[8] Council on Tall Buildings and Urban Habitat, https://www.skyscrapercenter.com/building/socar-tower/2606

[9] Atlas Obscura, https://www.atlasobscura.com/places/alphabetic-tower

[10] Den Hartog, J.P., 1947. Mechanical Vibrations. McGraw-Hill, New City.

[11] Bishop, R.E.D. and Welbourn, D.B., 1952. The problem of the dynamic vibration absorber. Engineering, London, 174 and 769. 
[12] Snowdon, J.C., 1959. Steady-state behavior of the dynamic absorber. Journal of the Acoustical Society of America, 31, 10961103.

[13] Falcon, K.C., Stone, B.J., Simcock, W.D. and Andrew, C., 1967. Optimization of vibration absorbers: a graphical method for use on idealized systems with restricted dumping. Journal Mechanical Engineering Science. 9, 374381.

[14] Ioi, T. and Ikeda, K., 1978. On the dynamic vibration damped absorber of the vibration system. Bullet in the JSME 21, 6471.

[15] Warburton, G.B., 1982. Optimum absorber parameters for various combinations of response and excitation parameters, Earthquake Engineering and Structural Dynamics, 10, 381401.

[16] Sadek, F., Mohraz, B., Taylor, A.W. and Chıng, R.M., 1997. A method of estimating the parameters of tuned mass dampers for seismic applications, Earthquake Engineering and Structural Dynamics, 26, 617635.

[17] Comeon, M.N.S. and Arfiadi, Y., 1998. Optimum design of absorber for MDOF structures. Journal of Structural Engineering-ASCE, 124, 12721280.

[18] Marano, G.C., Greco, R. and Chiaia, B., 2010, A comparison between different optimization criteria for tuned mass dampers design. Journal of Sound and Vibration,329, 48804890 .

[19] Singh, M.P., Singh, S. and Moreschi, L.M., 2002. Tuned mass dampers for response control of torsional buildings, Earthquake Engineering and Structural Dynamics, 31, 749769.

[20] Desu, N.B., Deb, S.K., Dutta, A., 2006. Coupled tuned mass dampers for control of coupled vibrations in asymmetric buildings, Struct Control Hlth., 13, 897916.

[21] Pourzeynali, S., Lavasani, H.H., Modarayi, A.H., 2007. Active control of highrise building structures using fuzzy logic and genetic algorithms, Eng. Struct, 29, 446-357.

[22] Zhan, W., Cui, Y., Feng, Z., Cheung, K.C., Lam, J. and Gao, H., 2013. Joint optimization approach to building vibration control via multiple active tuned mass dampers. Mechatronics, 23(3), 355-368.

[23] Mohebbi, M. and Joghataie, A., 2012. Designing optimal tuned mass dampers for nonlinear frames by distributed genetic algorithms. The structural Design of Tall and Special Buildings, 21(1), 57-76.

[24] Mohebbi, M., Shakeri,K., Ghanbarpout,Y. and Majzoub,H., 2013. Designing optimal multiple tuned mass dampers using genetic algorithms (Gas) for mitigating the seismic response of structures. Journal of Vibration and Control, 19(4), 605-625.

[25] Xiang, P. and Nishitani, A., 2015. Optimum design of tuned mass damper floor system integrated into bending-shear type building based on $\mathrm{H} \infty, \mathrm{H} 2$ and stability maximization criteria. Structural Control and Health Monitoring, 22(6), 919-938.

[26] Liu, Y., Wang, K., Mercan, O., Chen, H. and Tan, P., 2020. Experimental and numerical studies on the optimal design of tuned mass dampers for vibration control of high-rise structures. Engineering Structures, 211, 110486.

[27] Steinbuch, R., 2011. Bionic optimization of the earthquake resistance of high buildings by tuned mass dampers. Journal of Bionic Engineering, 8, 335-344. 
[28] Farshidianfar, A., Soheili, S., 2013. Ant colony optimization of tuned mass dampers for earthquake oscillations of high-rise structures including soil structure interaction, Sile Dynamic Earthquake Eng., 51, 14-22.

[29] Leung, A.Y.T., Zhang, H., Cheng, C.C. and Lee, Y.Y., 2008. Particle optimization of TMD by non-stationary base excitation during earthquake, Earthquake Engineering and Structural Dynamics, 37, 1223-1246.

[30] Leung, A.Y.T. and Zhang, H., 2009. Particle swarm optimization of tuned mass dampers, Engineering Structures, 31, 715-728.

[31] Bekdas, G. and Nigdeli, S.M., 2017. Metaheuristic-based optimization of tuned mass dampers under earthquake excitation by considering soil-structure interaction, Soil Dynamics and Earthquake Engineering, 92, 443-461.

[32] Nigdeli, S.M. and Bekdas,G., 2017. Optimum tuned mass damper design in the frequency domain for structures, KSCE Journal of Civil Engineering, 21(3), 912-922.

[33] Zhang, H. and Zhang, L.J., 2017. Tuned mass damper system of high-rise in take towers optimized by improved harmony search algorithm, Engineering Structures, 138, 270-282.

[34] Nigdeli, S.M., Bekdas, G. and Aydin, A., 3-7 May 2017. Metaheuristic-based optimization of tuned mass dampers on a single degree of freedom structures subjected to nearfault vibrations, $3^{\text {rd }}$ International Conference on Engineering and Natural Sciences (ICENS 2017), Budapest, Hungary.

[35] Bekdas, G., Nigdeli, S.M. and Aydin, A., 8-10 May 2017. Optimization of Tuned Mass Damper for Multi-Storey Structures by using Impulsive Motions, $2^{\text {nd }}$ International Conference on Civil and Environmental Engineering (ICOCEE 2017), Cappadocia, Turkey.

[36] Bekdas, G. and Nigdeli, S.M., 2013. Optimization of tuned mass damper with harmony search. Metaheuristic Applications in Structures and Infrastructures, 345-371.

[37] Farshidianfar, A. Soheili, S., 2013. ABC optimization of TMD parameters for tall buildings with soil structure interaction, Interact Multiscale Mech, 6, 339-356.

[38] Nigdeli, S.M. and Bekdas,G., 2015. Teaching-Learning-Based Optimization for Estimating Tuned Mass Damper Parameters, $3^{\text {rd }}$ International Conference on Optimization Techniques in Engineering (OTENG' 15), 7-9 November, Rome, Italy.

[39] Nigdeli, S.M., Bekdas, G. and Yang, X-S, 2017. Optimum Tuning of Mass Dampers by Using a Hybrid Method Using Harmony Search and Flower Pollination Algorithm In: Harmony Search Algorithm Advances in Intelligent Systems and Computing, vol 514, Del Ser J. (eds) Springer, pp. 222-231.

[40] Yucel, M., Bekdaş, G., Nigdeli, S.M. and Sevgen, S., 2019. Estimation of optimum tuned mass damper parameters via machine learning. Journal of Building Engineering, 26, 100847.

[41] Bekdas, G., Nigdeli, S.M. and Yang, X-S., 2018. A novel bat algorithm based optimum tuning of mass dampers for improving the seismic safety of structures, Engineering Structures 2018, 159:89-98.

[42] Bekdas, G., Kayabekir, A.E., Nigdeli, S.M. and Toklu, Y.C., 2019. Transfer Function Amplitude Minimization for Structures with Tuned Mass Dampers Considering SoilStructure Interaction, Soil Dynamics and Earthquake Engineering, 116: 552-562. 
[43] Bekdas, G., Ulusoy, S. and Nigdeli, S.M., 2018. Optimum Tuning of Mass Dampers by Impulsive Motions and Several Metaheuristic Methods $3^{\text {rd }}$ International Conference on Civil and Environmental Engineering (ICOCEE), 24-27 April 2018, Izmir, Turkey.

[44] Mathworks, MATLAB, 1992. The Mathworks Inc, Natick, MA.

[45] FEMA P-695. Quantification of Building Seismic Performance Factors. Washington.

[46] Rao, R., 2016. Jaya: a simple and new optimization algorithm for solving constrained and unconstrained optimization problems, International Journal of industrial engineering computations, 7(1), 19-34. 